\section{Commentary: New strategies for old techniques}

\author{
Philip W. Carrott, MD, ${ }^{\mathrm{a}, \mathrm{b}}$ and R. Taylor Ripley, MD ${ }^{\mathrm{a}}$
}

Ramadan and colleagues ${ }^{1}$ have outlined a reliable method for testing the impact of varying concentrations of oxaliplatin with in vivo lung perfusion (IVLP). This group has pioneered ex vivo lung perfusion for treatment of donor lungs for transplant. Now, they have added the effort to treat the lung in vivo for cancer.

IVLP for metastatic disease is an old technique. When chemotherapy was first administered, the toxicity to patients was severe and the efficacy was low. Therefore, directly administering chemotherapeutics to regions with the tumors was an early initiative to treat solid tumors. In 1950, Klopp and colleagues ${ }^{2}$ published a technique for intra-arterial administration of nitrogen mustards in 10 patients. Among those patients with mostly head and neck tumors, 2 died within 24 hours. Not surprisingly, they found that the systemic toxicities were the same unless venous return was occluded. Creech and colleagues ${ }^{3}$ made several advancements in regional isolation and extracorporeal circuits for delivery of chemotherapeutics in the 1950s. Although much of their work focused on extremity perfusion for melanoma and sarcoma, they reported IVLP in 1 patient in this publication. Seven doses of nitrogen mustard were infused over 30 minutes after isolation of the lung. Creech and colleagues administered blue dye into the circuit to confirm minimal systemic leak of the nitrogen mustard. Interest in IVLP specifically for metastases increased in the 1980s. Minchin and colleagues ${ }^{4}$ reported that IVLP with doxorubicin was possible in 3 patients in 1984. They reported the concentration of doxorubicin in both the tumor and the normal lung. Several early-phase trials were reported. Pass and colleagues ${ }^{5}$ administered tumor necrosis

From the a Division of General Thoracic Surgery and ${ }^{\mathrm{b}}$ Transplantation and Circulatory Support, The Michael E. DeBakey Department of Surgery, Baylor College of Medicine, Houston, Tex.

Disclosures: Authors have nothing to disclose with regard to commercial support.

Received for publication March 23, 2020; revisions received March 23, 2020; accepted for publication March 24, 2020; available ahead of print April 5, 2020.

Address for reprints: R. Taylor Ripley, MD, Department of Surgery, Division of General Thoracic Surgery, Baylor College of Medicine, Houston, TX 77030 (E-mail: R.Taylor.Ripley@bcm.edu).

J Thorac Cardiovasc Surg 2021;161:1636-7

$0022-5223 / \$ 36.00$

Copyright (c) 2020 by The American Association for Thoracic Surgery

https://doi.org/10.1016/j.jtcvs.2020.03.071

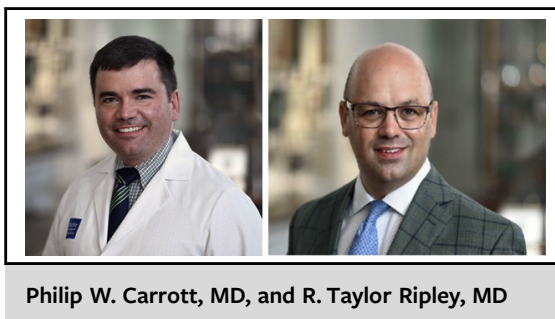

CENTRAL MESSAGE

Ramadan and colleagues report a

porcine model to develop

improved strategies to treat

pulmonary metastases with oxa-

liplatin delivered by isolated

in vivo lung perfusion.

factor- $\alpha$ and interferon- $\gamma$. Burt and colleagues ${ }^{6}$ performed a phase I study of IVLP for isolated metastases from sarcoma. Despite the long history of IVLP, the procedure remains experimental and is certainly not widely adopted.

Ramadan and colleagues work with experimental animal studies is important to determine whether this field should advance. The use of a porcine model establishes the pharmacodynamics and pharmacokinetics necessary for phase I and II human studies. However, 2 points in the experimental design should be noted. First, the dose escalation doubles at each step. This increase is acceptable at lower concentrations; however, the increase may be too large at the upper concentrations. The authors observed that $40 \mathrm{mg} / \mathrm{L}$ was safe and $80 \mathrm{mg} / \mathrm{L}$ was not. Yet, no concentration between these levels was tested. Second, the toxicity was assessed with a 3-day survival model. They state that oxiplatin rarely has pulmonary toxicity with 1 systemic cycle. Yet, they administer 1 cycle directly to the pulmonary circulation with 5 times the concentration of systemic administration. This administration is not equivalent to systemic dosing; therefore, longer-term assessment of toxicity is necessary and should be considered with future trials.

Although additional preclinical trials should help transition to human trials, the authors should be commended for continuing to lead this field with advances that are already impacting patient care. The step-wise systematic approach is exactly how we should proceed with introduction of these therapies into humans. 


\section{References}

1. Ramadan K, Gomes B, Pipkin M, Olkowicz M, Bojko B, Mbadjeu Hondjeu AR, et al. A model to assess acute and delayed lung toxicity of oxaliplatin during in vivo lung perfusion. J Thorac Cardiovasc Surg. 2021;161:1626-35.

2. Klopp CT, Alford TC, Bateman J, Berry GN, Winship T. Fractionated intra-arterial cancer; chemotherapy with methyl bis amine hydrochloride; a preliminary report. Ann Surg. 1950;132:811-32.

3. Creech O Jr, Krementz ET, Ryan RF, Winblad JN. Chemotherapy of cancer: regional perfusion utilizing an extracorporeal circuit. Ann Surg. 1958;148:616-32.
4. Minchin RF, Johnston MR, Aiken MA, Boyd MR. Pharmacokinetics of doxorubicin in isolated lung of dogs and humans perfused in vivo. J Pharmacol Exp Ther. 1984;229:193-8.

5. Pass HI, Mew DJ, Kranda KC, Temeck BK, Donington JS, Rosenberg SA. Isolated lung perfusion with tumor necrosis factor for pulmonary metastases. Ann Thorac Surg. 1996;61:1609-17.

6. Burt ME, Liu D, Abolhoda A, Ross HM, Kaneda Y, Jara E, et al. Isolated lung perfusion for patients with unresectable metastases from sarcoma: a phase I trial. Ann Thorac Surg. 2000;69:1542-9.
See Article page 1626.

\section{Commentary: Perceived versus real threat... and the nuclear option}

\author{
Jacob A. Klapper, MD
}

In this manuscript, the group at the University of Toronto has demonstrated how their unparalleled expertise in the field of ex vivo lung perfusion may have benefits beyond lung transplantation. ${ }^{1}$ The rigor with which this current study was produced does indeed provide a blueprint for a potential phase I study of isolated lung perfusion for the treatment of colorectal metastases.

Again, it is very hard to argue with their methodology and technique, as this group is widely recognized as the world experts in ex vivo lung perfusion. In addition, it is only natural that they would consider the application of this technology to the field of thoracic oncology, where pulmonary mastectomies are commonly performed for a variety of histologies. Furthermore, the precedent for isolated organ perfusion exists in the treatment of metastatic disease to the liver and limb. ${ }^{2,3}$

I'll admit on first blush such an approach to pulmonary metastases seems appealing despite the morbidity of the procedure (as it's currently designed) and the real potential for delayed pulmonary toxicity. The question I keep coming

\footnotetext{
From the Division of Cardiothoracic Surgery, Duke University Medical Center, Durham, NC.

Disclosures: Author has nothing to disclose with regard to commercial support.

Received for publication March 26, 2020; revisions received March 26, 2020;

accepted for publication March 27, 2020; available ahead of print April 11, 2020.

Address for reprints: Jacob A. Klapper, Division of Cardiothoracic Surgery, DUMC

3954, Durham, NC 27710 (E-mail: Jacob.klapper@duke.edu).

J Thorac Cardiovasc Surg 2021;161:1637-8

0022-5223/\$0.00

Published by Elsevier Inc. on behalf of The American Association for Thoracic Surgery

https://doi.org/10.1016/j.jtcvs.2020.03.087
}

Check for updates

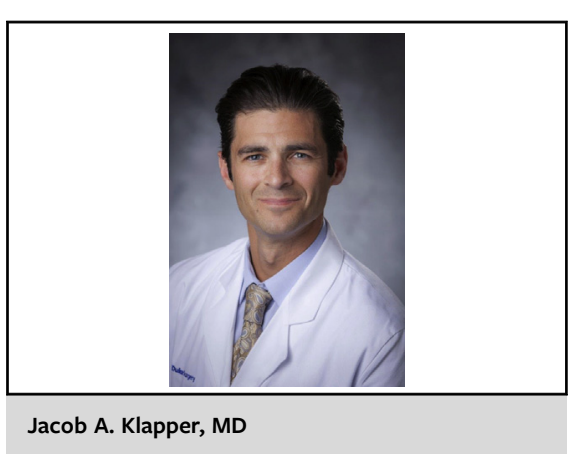

CENTRAL MESSAGE

Isolated lung perfusion. It can be done. Should it be done?

back to, however, is who would want or need such an operation? I would surmise that the ideal candidate would be an individual with unilateral lung metastases that are either too numerous, too large, or in unfavorable anatomic locations that standard surgical resection is not possible. This would likely make up a small subset of patients, a group that would be further reduced in size by fact that many with lung disease would also have other sites of metastatic disease.

Another theoretical point to consider is the perceived threat versus the real threat of lung metastases. In other words, how life-limiting are lung metastases that we would need a procedure like isolated lung perfusion. For instance, most would agree that lung metastases, unlike implants in other organs, ie, bone or brain, are rather indolent lesions that cause no pain and rarely negatively impact pulmonary function. In addition, we have debated for years what, if any, survival benefit is conferred from the conventional removal of these lesions.

In sum, the importance of accurately assessing whether a perceived threat is a real threat is that many times the 